\title{
Deliberation, Dialogue and Debate: Why Researchers need to Engage with Others to Address Complex Issues
}

\author{
Ajoy Datta
}

\begin{abstract}
As societies have become more differentiated, policy issues are increasingly being analysed using concepts and ideas from the complexity sciences. Policy change involving diverse stakeholders interacting with one another in ways that are shaped by power and politics are increasingly characterised by contestation and unpredictability. Stakeholders other than researchers are collecting information and producing their own knowledge to add new perspectives to those of, and contest the power given to, researchers and their advice. Against this backdrop, I argue that traditional approaches to communicating research to policymakers are inadequate. Researchers now share the field of knowledge production and communication with many others, and where appropriate, those who view their role in relation to policy, should be prepared to engage with stakeholders affected by policy issues and expose their findings to human interaction, review and scrutiny by others.
\end{abstract}

\section{Introduction}

Societies, communities and organisations are increasingly being viewed through a complexity lens which conceptualises them (to different degrees) as human systems made up of multiple actors interacting with one another in often unpredictable ways and affected by factors within and beyond the immediate context. This has implications for our understanding of how policy is made and the role of researchers and research institutions in the process. Communicating research can make a meaningful difference to policymaking processes, but it is clear that the simple linear model, where research results are disseminated to target audiences who assimilate this and act upon it, is too simplistic. As a result I argue in this article that where issues are deemed complex, it is not enough for researchers to communicate unidirectionally with elite policymakers and expect their findings to lead to changes in policy and practice. Instead I suggest researchers consider engaging in a post-normal science, where they are prepared to engage with a range of stakeholders (including researchers in other disciplines) in a conversation using multiple 'languages' at various stages of the research process.
The article is organised as follows:

- The next section provides a brief overview of the key concepts from the complexity sciences and what this means for policymaking processes;

- Section 3 sets out the implications of this for engaging with policy, making the case for researchers to engage with multiple stakeholders;

- Section 4 discusses how researchers select: stakeholders to deliberate with, when to engage with them, and what methods and approaches to use; and highlights the role of intermediaries in facilitating engagement processes;

- Section 5 plots implications for researchers;

- Section 6 considers what this means for their institutions and funders; while

- The final section concludes.

\section{Complexity, participation and power relations}

Things in life are unlikely to happen in exactly the same way twice. This means deterministic thinking in which the future is seen as a straightforward extrapolation of past trends is unlikely to be helpful in addressing social, political and economic phenomena. Systems (such as societies and organisations) are increasingly being

IDS Bulletin Volume 43 Number 5 September 2012 (c) 2012 The Author. IDS Bulletin (c) 2012 Institute of Development Studies Published by Blackwell Publishing Ltd, 9600 Garsington Road, Oxford OX4 2DQ, UK and 350 Main Street, Malden, MA 02148, USA 
scrutinised using a (not so) new set of concepts and ideas from the complexity sciences. Through this lens, many of the systems which humans inhabit are characterised to varying degrees by interconnected and interdependent elements and dimensions, multiple feedback loops where changes emerge - often unpredictably - from the interaction of its parts and actors (who react to the system as a whole and to each other), such that the whole is different to the sum of the parts (see Ramalingam and Jones 2008).

In such systems, there is often limited knowledge about problems, dynamics and capacities which tend to be distributed at different levels and across a range of stakeholders. There tend to be several plausible and equally legitimate interpretations and perspectives on the questions policy must address, which are often conflicting and divergent. And there can also be limited knowledge on cause and effect and appropriate policy actions, as well as a high level of unpredictability. The capacity to act cannot be controlled by one actor (such as centrally located policymakers). Groups not linked by formal hierarchies (such as non-governmental organisations (NGOs), community groups and social movements) may have an ability to selforganise and work more coherently towards a common goal (than say government authorities) as they might have a stronger understanding of the local context and are more likely to have ownership over solutions. Participation of multiple stakeholders, amongst other things, becomes critical to addressing complex problems. However, power asymmetries mean that diverse stakeholders are not always afforded formal space to participate in formal knowledge production processes.

Against this background, non-elites (such as farmers, patients, consumers, amongst others), have increasingly mobilised to contest the power given to researchers and their advice and have added new perspectives to knowledge gathered through scientific processes by collecting information and producing their own knowledge. Groups such as HIV and AIDS activists, toxic waste campaigners and those campaigning for the removal of phthalates from plastic bottles, have made claims based on their experiential knowledge. This has gradually led to a broadening out of people who are considered as legitimate actors in shaping policy outside of government. These include both specialists such as researchers, as well as non-specialists such as generalist media outlets, civil society practitioners, business people, and members of the public (Leach et al. 2005).

\section{Implications for communicating research 3.1 Why traditional methods are inadequate}

Decisions about how to use whose knowledge to deliver policy are subsequently bound up with the policymaking process in a reflexive and complex set of relationships, shaped by power and interests and are far from straightforward (Shaxson et al. 2012). For instance, research and other types of knowledge addressing complex issues, no matter how robust, tends not to translate neatly into a set of policy actions. Where there is uncertainty and underlying values are contested, knowledge producers (such as researchers) in any one field tend not to speak with one voice. Research findings and the methods through which they are derived can be interpreted in a number of ways, contested, challenged and rejected for a variety of reasons. And research is just one of many competing factors influencing policy decisions and changes in practice (see Court et al. 2004; Young and Mendizabal 2009). As a result, it is clear that the simple linear model, where research results are disseminated to target audiences who assimilate this new knowledge and act upon it, is too simplistic (Barnard et al. 2006).

\subsection{The case for deliberative dialogue processes}

As Funtowicz and Ravetz (1992) argue, complex problems require a post-normal science.

Researchers no longer have a monopoly over knowledge production and communication. The authority of research evidence increasingly comes from it being exposed to human interaction, review and scrutiny. And given that policies do not change because of a single piece of evidence, researchers need to engage with broader arguments informed by evidence from a variety of sources, and appeals to values as well as interests (Mendizabal $2011 \mathrm{a}$ ). As such, researchers are increasingly willing to enter into dialogue with stakeholders affected by the issue they are working on.

Participation in carefully managed and structured processes of deliberation embedded in inclusive, face-to-face fora, focusing on processes of contestation and argument, building and working with critical voices, rather than avoiding them and eliciting reasoned inputs, can inform 
and improve the foundations of policy and action (Jones 2011). However, this is not necessarily a new phenomenon in the so-called 'developing world', where the perspectives of the citizenry for instance, are being combined with the knowledge of technical experts in areas such as health, agriculture and ecology, and where deliberative processes are a well-established phenomenon constructed mainly at the community level (Leach et al. 2005).

But we should remember that not all researchers see policy engagement as part of their role. Researchers can and have adopted a variety of roles in relation to policy. Pielke (2007) for instance, describes four such roles: pure scientists are only interested in doing research; science arbiters respond to specific questions from policymakers but do not express policy preferences; issue advocates aim to influence policy in a particular direction; and honest brokers clarify and potentially expand the policy options available to decision-makers. Although boundaries between roles are blurred, engagement processes may be more suited to those who see themselves as issue advocates and honest brokers. Moreover, the political context, which may be characterised by hierarchical and particularistic relations, may not be conducive to open and frank discussions amongst diverse stakeholders.

Nevertheless, intentions to engage for substantive reasons (as above) should not be confused with normative and instrumental reasons to do so. A normative approach rests on a commitment to empower stakeholders, particularly those with marginal or excluded interests, rather than dominant institutions or elite social groups, while instrumental motives can take the form of social intelligence and gauging the likelihood of adverse responses to specific policy actions (neither of which are necessarily undesirable). However, government departments and science institutions have on occasion been charged with the claim of using engagement processes to provide legitimacy before consultation has begun, put off making a decision, provide cover for an unpopular decision already made or manage their public reputation (Datta 2011). Although these different intentions are not mutually exclusive, it is crucial that organisers and participants have an honest discussion about the purpose of deliberative processes from the very start, a process which should then inform an appropriate set of questions and tools - issues I turn to next.

\section{Deliberative engagement: some key issues 4.1 'Selecting' stakeholders}

Formal deliberative engagement processes are often criticised for their inability to reach a scale that can meet mathematical notions of being representative of a population (Sciencewise 2008a). But others argue that public engagement need not be a statistically significant exercise or a nationwide democratic process to be valid. What is gained from smaller, more interactive processes is a depth of discussion that is often lost in large-scale public engagement (Gavelin et al. 2007). Nevertheless, in selecting participants for formal engagement processes, there is a need to clarify who the key policy actors are and how they are chosen.

In his discussion of a citizen's jury on food and farming issues in Zimbabwe, Rusike (2005) describes criteria used to select participants: they had to be full-time residents in rural areas and farming had to be a significant part of their livelihood; there had to be equal gender representation from each district; and they had to have a broad knowledge of rural issues and be sufficiently articulate and confident in discussion in Shona or Ndebele. Such extensive criteria appeared to considerably limit who could participate, raising questions about how representative the group was. In South Africa, an arguably more 'democratic' tool was used to select participants for a Foresight programme to inform investments in research and development in science and technology in the mid-1990s (see Tomei et al. 2006: 13). Co-nomination, a surveybased selection technique, allowed stakeholders and the broad community to participate in an open exercise of identifying individuals and experts to participate.

\subsection{Choosing when to engage}

Figure 1 describes the stages of the research process at which the public can be engaged. Where problems are complex, 'downstream' engagement where researchers aim to apply research findings to affected populations, is likely to be inadequate. The nano-dialogue experiments, a series of experiments undertaken by UK organisations in the 2000 s to engage the public on the emerging issue of nanotechnologies, were an example of dialogue 
Figure 1 When public engagement should take place

'UPSTREAM'

Direct communication/deliberative

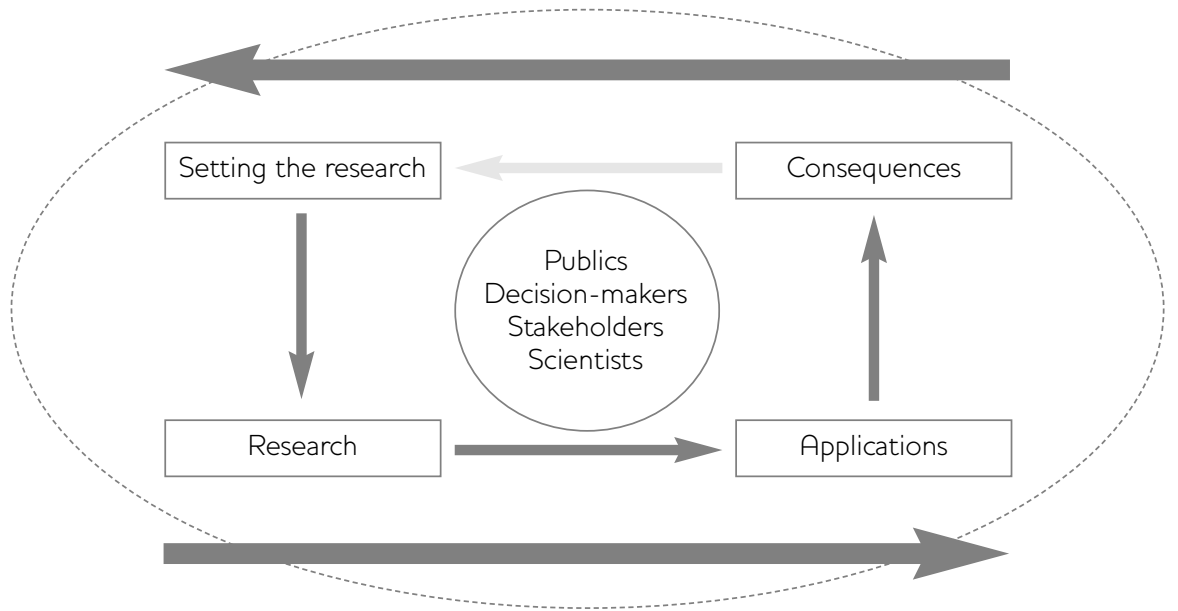

'DOWNSTREAM'

Mass communication

Source Whitmarsh et al. (2005).

amongst scientists and members of the public, moving 'upstream' to inform decision-making on financial investments and long-term objectives.

However, fostering meaningful engagement on a topic the general public knew very little about was challenging. The fact that nanotechnologies were in the early stages of their development meant that discussions often lacked purpose. Deliberations were limited to applications that members of the public could relate to, such as consumer goods and medical applications, which often frustrated researchers. Questions were raised around whether experiments may have been conducted too early in the development of nanotechnologies (Chilvers 2006). Some have argued that stakeholders could be consulted at a stage when value judgements become important, and not necessarily at the first stage of problem identification. But organisers may be better off considering different forms of engagement at different points of the research cycle (Stilgoe 2007).

\subsection{Selecting appropriate methods}

Like a research project, methods employed to engage stakeholders in deliberative processes should be informed by high-level research questions. Several case studies highlight the importance of asking the right questions in line with the preferences of the stakeholders involved (Sciencewise 2008a). A single deliberative engagement event is unlikely to provide all the inputs needed to support deliberation. Public engagement processes that draw on a range of methods and approaches to elicit a diversity of views are likely to work better (Warburton 2008). For instance, a review of engagement around cyber trust and crime prevention in the UK suggested a mixed methodological approach, drawing on technological demonstrations that provided hands-on experience, a focus on current stories in the media, and provocative quotes on issues of security, privacy and trust acted as a catalyst for discussion (Sciencewise 2008b). And one cannot overemphasise the role trust plays in allowing diverse actors who do not necessarily know each other initially, to work together over extended periods of time (Habibie et al. 2002).

\subsection{The role of intermediaries}

In fostering interaction between diverse stakeholders there might be a need for specialist actors to facilitate the process. The print, broadcast and online media have to some extent facilitated this interaction, by publicising and critiquing research findings, promoting and widening debate, and demanding accountability. But spurred on by rapid developments in information and communication technologies over the last decade, these roles are increasingly being played by other intermediaries who contribute to interpreting information, creating 
new knowledge and fostering social learning and innovation in a variety of ways by, for instance, strengthening relationships and networks of actors or contributing to collective engagement around an issue (Shaxson et al. 2012).

These intermediaries can sit: outside government, such as prominent academics and communication/ public engagement specialists within universities, networks, think tanks and civil society organisations; inside government, such as strategy units and evidence teams or; somewhere in between, including high-level commissions, science advisory councils and legislative committees (ibid.). Given the asymmetries that may be apparent among stakeholders, based on information and knowledge, economic strength and resources, political power, negotiation skills or simply motivation and the capacity to take the initiative, intermediaries can often help level the playing field among participants by developing relevant capacities (Habibie et al. 2002).

\section{Implications for researchers}

Even with the help of intermediaries, researchers who aim to engage with policy have often had to alter their own mindset and approach. Such researchers tend to do more than educate, teach or inform other stakeholders about their work and have listened to the views of others, learned from them and have been more self-reflective. Drawing parallels with action research approaches in agriculture, taking this approach means researchers are no longer perceived as neutral and objective observers of the 'system', but take on an active role and admit to be part of a (value-based) decision-making process within the 'system' (see for instance BSA 2010). When there are power asymmetries between 'experts' and 'lay' people, researchers have often taken a 'back seat', or have disempowered themselves. And changing roles from 'doing research for development' to 'doing research as development' requires skill, experience and some intuition (Halberg and Larsen 2002).

But there are probably many researchers who are already engaging in these practices formally, or more likely, informally. They may be adept at networking and may be well connected with a variety of stakeholders. And they know that policymakers, particularly in some developing countries where institutional capacity may not provide formal channels, often rely on their own networks to access and interpret information. In
Indonesia, for instance, informal links are hugely dominant in terms of how policymakers go about looking for information and in the way stakeholders engage with one another (Datta $e t$ al. 2011). Many policymakers seem to prefer this, as it is characterised by high levels of trust and credibility, and as such favour links with individuals over those with organisations. However, this is not necessarily a 'fair' system with some individuals able to enjoy excessive influence over those in power by virtue of, for instance, being part of an extended kin network. The lesson, nonetheless, is to understand the system and how to move through it and engage with different actors using appropriate 'languages'. As Shergold (2011) puts it, influencing policy is a matter of using evidence to build alliances and negotiate compromises to create political will and public support.

Researchers also need to move beyond the rhetoric of multi-, inter- and trans-disciplinarity and make it a reality. The latter is particularly crucial for so-called 'wicked' problems, such as designing climate-compatible policies, which cannot be solved by researchers in a single discipline, nor even by multidisciplinary teams (where members of a team work on different elements of the problem independently or combine their different disciplines into a single approach). In complex, unpredictable situations, where decisions need to be made and there is not time to conduct rigorous research to come up with answers, multiple stakeholders, including researchers, policymakers and members of the public need to develop a shared conceptual framework drawing together disciplinary specific theories, concepts and approaches to addressing the problem. However, this is not easy to do. Halberg and Larsen (2002) suggest that considerable resources are required for such work, as developing a common approach requires substantial time and energy as well as good leadership.

\section{Implications for research institutions and funders}

If researchers are to play more of a role in engaging with broader policy debates, their institutions and funders (which largely shape their incentives to act) will need to do more to facilitate this. Many researchers who wish to engage in more deliberative work face institutional constraints such as lack of time, support, resources. Eames et al. (2008), for 
instance, argue for greater recognition of outputs other than those published in peer-reviewed journals. Most researchers have not been trained to engage with non-specialists such as the public and media. Barriers also include a narrow view of what counts as research evidence. Further, in many research institutions, public engagement is not a priority, and it can be difficult for researchers to convince their employers and funding agencies that it is worth investing in.

In a workshop held by the Nanotechnology Engagement Group (NEG) in 2006, participants called for a number of changes to encourage and recognise the value of stakeholder input in research and development. These included a requirement for funding bodies to stress the need for dialogue-focused engagement alongside oneway engagement approaches such as lectures; and a change in institutional culture in universities to encourage and recognise the value of stakeholder input in research and development (Gavelin et al. 2007). In addition, a report by the Royal Society (2006) on factors that affect researchers' involvement in deliberative engagement, makes demands for more specialist training and other forms of practical support, such as mentoring.

However, even with adequate support, researchers and their institutions need to be realistic about what they can achieve and the extent to which any changes that do occur can be attributed to their own work. Rich (2004) suggests that an investment in engagement will not necessarily lead to a proportional increase in influence based on its findings. Promoting outcomes usually relies on behaviour change across a wide network of actors and social relationships, and attributing change to a particular intervention becomes very challenging. Further, researchers may offer an independent voice, provide credibility to an idea and help popularise an approach, but decisions are ultimately made by those in public office (Mendizabal 2011b). The best researchers and research institutions can hope for is to make a contribution to policy discussions (whether behind closed doors or in public) and/or for policymakers and shapers to at least consider an alternative course of action (which they may well disregard). Ultimately researchers and their institutions may be better off knowing if and when to engage with whom. And when they do, they need to know how to do it well.

\section{Conclusion}

The increasing realisation of the complex, nonlinear and multifactorial nature of most policymaking processes has led to a gradual shift in behaviour of researchers interested in engaging with policy, from supply-driven research communication to, where appropriate, more deliberative interaction with a wider range of stakeholders in a variety of spaces and places. However, real intentions behind deliberative processes are not always clear - whether for substantive, normative or instrumental, which are not necessarily mutually exclusive. If researchers aim to engage in dialogue through structured processes, experience has shown that careful planning is required to clarify intentions, select who to engage with, when to engage, and how best to do so. Skilled intermediaries can be adept at facilitating engagement processes by, for instance, providing information to participants, developing their capacities, and thus making efforts to redress power asymmetries.

Nevertheless, some researchers will need to alter their own mindsets. In some cases this may mean working in inter-, multi- and/or trans-disciplinary research teams, admitting to being part of a value-based system, and disempowering themselves in relation to other stakeholders such as members of the public. But stakeholder engagement is not a new phenomenon amongst researchers. Some have been engaging with different stakeholders for centuries, but institutions are not necessarily set up to facilitate deliberative engagement. Many commentators have thus called on research institutions to provide researchers with the right incentives to: engage effectively, draw on a wide range of expertise to enable them to contribute to policy and political processes coupled with realistic expectations as to what they can collectively achieve.

Research on how institutions have responded to such calls in recent years would be helpful in this regard. Moreover, whilst much has been written on how researchers in more 'developed' societies have engaged with a post-normal science and cross-disciplinary work, this is a relatively unexplored issue in more 'developing' societies where uncertainty and urgency are arguably greater in the context of rapid economic and social change. These and other questions could usefully form the basis of future research. 


\section{References}

Barnard, G.; Carlile, L. and Basu Ray, D. (2006) Maximising the Impact of Development Research: How can Funders Encourage more Effective Research Communication, Department for International Development/IDS/International Development Research Centre

BSA (2010) The Public Engagement Triangle, London: British Science Association

Chilvers, J. (2006) Engaging Research Councils? An Evaluation of Nanodialogues Experiment in Upstream Public Engagement, Birmingham: University of Birmingham

Court, J.; Hovland, I. and Young, J. (2004) Bridging Research and Policy in International Development: Evidence and the Change Process, London: Intermediate Technology Development Group

Datta, A. (2011) Lessons from Deliberative Public Engagement Work: A Scoping Study, London: Overseas Development Institute

Datta, A.; Jones , H.; Febriany, V.; Harris, D.; Kumala Dewi, R.; Wild, L. et al. (2011) The Political Economy of Policymaking in Indonesia: Opportunities for Improving the Demand For and Use of Knowledge, London: Overseas Development Institute

Eames, M.; Egmose Mortensen, J. and Adebowale, M. (2008) Towards a Community-led Agenda for Urban Sustainability Research: Insights from the Citizens' Science for Sustainability (SuScit) Project, London: SuScit

Funtowicz, S. and Ravetz, J. (1992) 'Emergent Complex Systems', Futures 26.6: 568-8

Gavelin, K.; Wilson, R. and Doubleday, R. (2007) 'Democratic Technologies'. Final Report of the Nanotechnology Engagement Group, London: Involve

Habibie, H.; Sriskandarajah, N. and Packham, R. (2002) Making Best Use of Limited Resources: Using Participative Action Research to Achieve Fodder Security with Smallholder Livestock Farmers in Indonesia, Proceedings of the European Branch of International Farming System Association (IFSA): 589-600

Halberg, N. and Larsen, C. (2002) Participatory Development Research: Enhancing Capacity within Applied Research - Case: Livestock, Aarhus: Faculty of Agricultural Sciences

Jones, H. (2011) Taking Responsibility for Complexity: How Implementation can Achieve Results in the Face of Complex Problems, London: Overseas Development Institute

Leach , M.; Scoones, I. and Wynne, B. (2005) Science and Citizens, Globalization and the
Challenge of Engagement, London/New York: Zed Books

Mendizabal, E. (2011a) Impact Evaluations, Research, Analysis... What is the Difference?, 22 June, Onthinktanks, http://onthinktanks.org/ tag/credibility/ (accessed 21 March 2012)

Mendizabal, E. (2011b) Daniel Kahneman Explains how Cognitive Illusions Skew our Thinking (About Think Tanks' Influence?'), 8 November,

Onthinktanks, http://onthinktanks.org/2011/ 11/08/daniel-kahneman-explains-howcognitive-illusions-skew-our-thinking-aboutthink-tanks-influence/ (accessed 3 March 2012)

Pielke Jr, R.A. (2007) The Honest Broker: Making Sense of Science in Policy and Politics, New York: Cambridge University Press

Ramalingam, B. and Jones, H. with Reba, T. and Young, John (2008) Exploring the Science of Complexity: Ideas and Implications for Development and Humanitarian Efforts, London: Overseas Development Institute

Rich, A. (2004) Think Tanks, Public Policy and the Politics of Expertise, New York: Cambridge University Press

Royal Society (2006) Survey of Factors Affecting Science Communication by Scientists and Engineers, London: People, Science and Policy Ltd (PSP)

Rusike, E. (2005) 'Exploring Food and Farming Futures in Zimbabwe: A Citizens' Jury and Scenario Workshop Experiment', in M. Leech, I. Scoones and B. Wynne, Science and Citizens, Globalization and the Challenge of Engagement, London/New York: Zed Books

Sciencewise (2008a) Nanotechnology Engagement Group: Research and Coordination of Six Dialogue Projects on Nanotechnology: Case Study, London: Department for Innovation, Universities and Skills

Sciencewise (2008b) Trustguide: Public Attitudes towards Trust in Information Communication Technologies (ICTS): Case Study, London: Department for Innovation, Universities and Skills

Shaxson, L.; Datta, A. and Young, J. (2012) Submission to the Science and Technology Committee on Science and International Development, London: Overseas Development Institute

Shergold, P. (2011) Seen but not Heard, 4 May, The Australian, www.theaustralian.com.au/news/ arts/seen-but-not-heard/story-e6frg8nf1226047007515 (accessed 3 March 2012)

Stilgoe, J. (2007) Nanodialogues: Experiments in Public Engagement with Science, London: Demos 
Tomei, J.; Lucas, K. and Vanner, R. (2006) A Review of Tools and Techniques for Community Foresight for Sustainability, London: SuScit (Citizen Science for Sustainability)

Warburton, D. (2008) Evaluation of the Research Councils UK Public Dialogue on UK Energy Research, London: Shared Practice

Whitmarsh, L.; Kean, S.; Russell , C.; Peacock, M. and Haste, H. (2005) From 'Dialogue' to
'Engagement'? Learning beyond Cases. Final Report for the Ministry of Research, Science and Technology, London: Cross Case Study Learning Group

Young, J. and Mendizabal, E. (2009) Helping Researchers Become Policy Entrepreneurs: How to Develop Engagement Strategies for Evidence-Based Policy Making, London: Overseas Development Institute 